\title{
Le rônier (Borassus akeassii B.O.G.) dans les parcs agroforestiers à Kokologho, Sakoinsé et Ramongo dans la province du Boulkiemdé, Centre-ouest du Burkina Faso
}

\author{
Joséphine YAMEOGO ${ }^{1, *}$, Yahaya SAMANDOULGOU2, Mamounata BELEM ${ }^{3}$ \\ 1. Agroforestière, DEF/INERA/CNRST. 03 BP 7047 Ouagadougou 03, BURKINA FASO. \\ 2. Gestionnaire des Ressources Naturelles. GRNSP, INERA Saria, 04 BP 864, BURKINA FASO \\ 3. Ethnobotaniste, DEF/INERA/CNRST. 03 BP 7047 Ouagadougou 03, BURKINA FASO. \\ *Auteur correspondant. Email : finayame@yahoo.fr
}

Original submitted in on $8^{\text {th }}$ February 2016. Published online at www.m.elewa.org on $30^{\text {th }}$ April 2016 http://dx.doi.org/10.4314/jab.v100i1.7

\section{RESUME}

Objectif : Le palmier rônier au Centre-ouest du Burkina Faso est méconnu bien qu'étant une composante de parcs agroforestiers. Cette étude a pour objectifs de faire une description de ces parcs ; apprécier les interactions rôniers-cultures ; identifier les modes, les contraintes de gestion et les souhaits d'amélioration des producteurs.

Méthodologie et résultats : Alors des recherches bibliographiques, des interviews ont été réalisées auprès de personnes ressources et des gestionnaires de parcs. Des inventaires ont été menés sur les parcelles à rôniers. Les résultats indiquent que les peuplements de rôniers sont vieillissants caractérisés par une densité moyenne de 49 plants/ha et une faiblesse de régénération de l'ordre de 3 plants/ha. Des actions de faibles intensités sont conduites pour la conservation de l'espèce notamment la régénération naturelle assistée ; les semis et la protection des plants. Les contraintes majeures sont le broutage intensif des plantules par les ruminants et la méconnaissance des usages du rônier.

Conclusion et application de la recherche : Partant des résultats de cette étude, les producteurs qui entretiennent et pratiquent des actions de renouvellement du patrimoine de rôniers doivent servir de base pour la gestion durable de l'espèce. Toute action visant une expansion du rônier dans les zones de faibles peuplements devrait commencer par des études similaires afin de caractériser ces peuplements, identifier les causes de faibles peuplements et les stratégies à adopter. Un renforcement des capacités et un transfert de technologies devraient être réalisés en faveur des populations qui reconnaissent l'importance socioéconomique du rônier. Celles-ci suggèrent que des renforcements de capacités soient réalisés en leur faveur dans le domaine de la gestion de l'espèce et de l'artisanat.

Mots clés : Borassus akeassii, parcs agroforestiers, gestion, Centre -ouest, Burkina Faso 
Yameogo et al. J. Appl. Biosci. 2016 Le rônier (Borassus akeassii B. O.G.) dans les parcs agroforestiers à Kokologho, Sakoinsé et Ramongo dans la province du Boulkiemdé, Centre-ouest du Burkina Faso

The palmyra (Borassus akeassii B.O.G) in agroforestry parklands at Kokologho, Sakoinsé and Ramongo in the province of Boulkiemdé, West-central Burkina Faso

\begin{abstract}
Objective: The African Palmyra palm in West-central Burkina Faso is unknown although it is a component of the agroforestry parklands. This study aims to make a description of these parklands; assess the interactions palmyra-crops; identify patterns, constraints of management and producer requests for improvement.

Materials and methods: So, literature searches and interviews were conducted with resource persons and palmyra parkland managers. Inventories were conducted on palmyra plots. The results indicated that the palmyra populations are aging, characterized by an average density of 49 plants / ha and a weakness regeneration around 3 plants / ha. Actions of low intensities are conducted for the conservation of species including assisted natural regeneration ; planting and protecting plants. Major constraints remain the intensive grazing of seedlings by ruminants and the ignorance of the palmyra uses.

Conclusions and application of findings : Based on the results of this study, the producers who maintain and practice palmyra heritage renewal actions should be the basis for the sustainable management of the species. Any action which aims the expansion of palmyra in areas with low populations should begin similar studies to characterize these populations, identify the causes of low populations and strategies to adopt. Capacity building and technology transfer should be made for the people who recognize the socioeconomic importance of palmyra. These suggest that reinforcements capacity be made in their favor in the field of management of the species and crafts
\end{abstract}

Keywords: Borassus akeassii, parklands, management, West-centre, Burkina Faso

\section{INTRODUCTION}

Dans le répertoire des espèces végétales de la strate haute des parcs agroforestiers du Burkina Faso figure le rônier (Ouédraogo, 1996 ; Yameogo et al., 2010). Remarquablement localisé dans les paysages de deux régions, il s'identifie en deux espèces que sont Borassus akeassii B.O.Gà l'Ouest et Borassus aethiopum Mart à l'Est. Initialement appelé Borassus flabellifer, les travaux de Bayton et al.(2006) aboutirent à la reconnaissance d'une nouvelle espèce qu'ils nommèrent Borassus akeassii. Des prospections partant des régions de l'Ouest à l'Est du pays ont permis d'identifier des ilots de rôniers dans les paysages champêtres du Centre-ouest. Ce type de rônier produit des fruits de couleur vert à maturité et répond à la description de Borassus akeassii (figure 1). D'une part, depuis plusieurs décennies les producteurs du Centre-ouest assurent le maintien et la protection de cette espèce dans leurs champs. D'autre part, les densités de ces rôniers dans les champs apparaissent faibles et variables. Cette situation reflète une importance controverse dans la région. Si l'importance socioéconomique du rônier est bien perceptible dans les régions de l'Est et de l'Ouest comme le rapportent plusieurs travaux (Ouédraogo, 1999 ; Yaméogo, 1999 ; Yaméogo et al., 2008), il n'est pas le cas au Centre-ouest. En effet, toutes les parties du rônier sont utilisées dans les domaines de l'alimentation, l'artisanat, la pharmacopée, le fourrage, l'énergie, la fertilisation du sol. Le commerce des produits issus de cette espèce constitue une activité socioéconomique dans les régions où elle est exploitée. Les précédents travaux ont été accentués sur les rôniers des deux régions si bien que des informations ne sont pas disponibles sur l'historique des peuplements du Centre-ouest, le mode de gestion et l'importance socioéconomique du rônier au sein de ces populations. Alors l'objectif global de l'étude est de faire une description des parcs à rôniers dans le paysage agraire du Centreouest. Spécifiquement elle vise à identifier les caractéristiques des peuplements de rôniers; apprécier les interactions rôniers-cultures; déterminer les modes de gestion des parcs à rôniers par les populations concernées. 


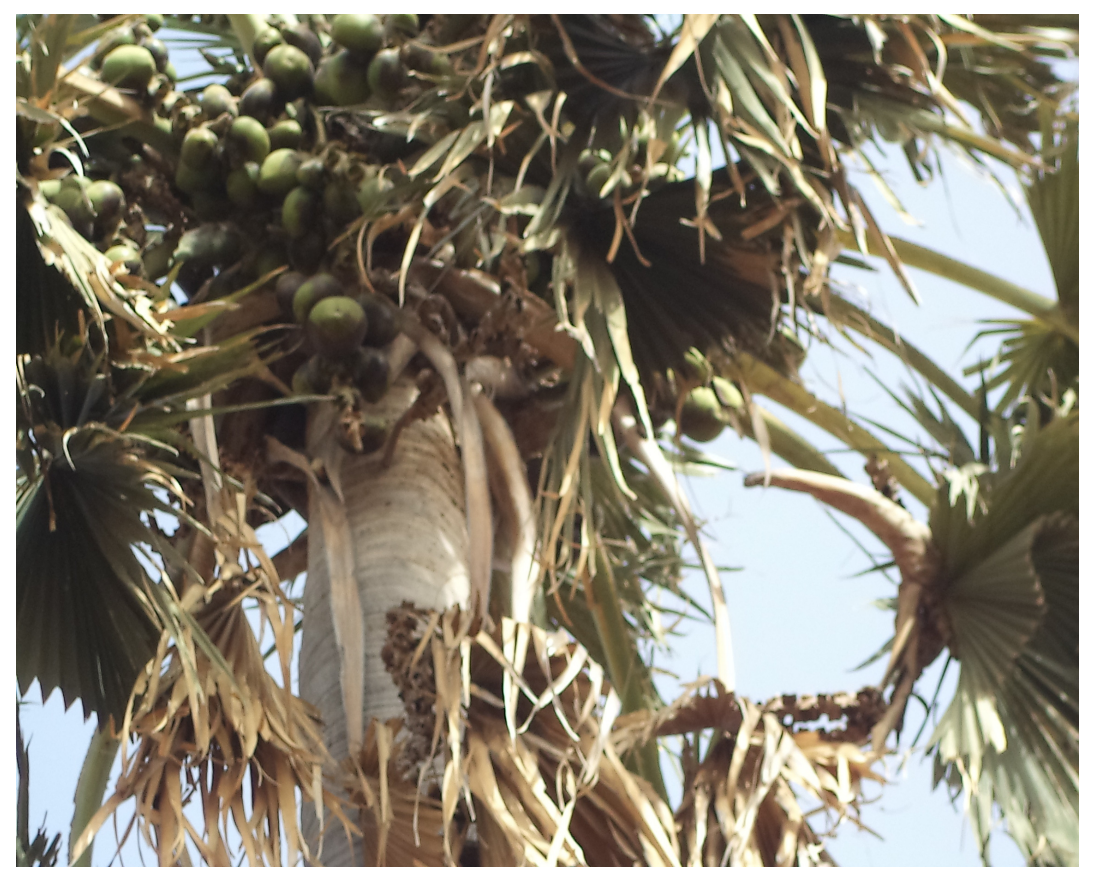

Figure 1: Houppier de Borassus akeassii comportant des fruits à Sakoinsé

\section{MATERIEL ET METHODES}

Le site de l'étude : Le site de l'étude est un ensemble de trois localités de la province du Boulkiemdé au Centreouest du Burkina Faso. II s'agit de la commune de Kokologho (12 11' 44" Nord; $1^{\circ} 52^{\prime} 15^{\prime \prime}$ Ouest), du village de Sakoinsé (12 $11^{\circ} 13^{\prime \prime}$ Nord $1^{\circ} 57^{\prime} 37^{\prime \prime}$ Ouest) et de la commune de Ramongo (12 $12^{\circ} 17^{\prime \prime}$ Nord $2^{\circ} 11^{\prime} 07^{\prime \prime}$ Ouest). Le climat de la province est de type nordsoudanien avec des précipitations moyennes annuelles variant entre 600 et $900 \mathrm{~mm}$. La température moyenne annuelle est de $27,5^{\circ} \mathrm{C}$ à $28^{\circ} \mathrm{C}$. La Province du Boulkiemdé se localise dans le domaine phytogéographique soudanien. Les formations végétales sont des savanes arbustives prédominantes constituées d'arbustes ne dépassant pas 7 mètres et des savanes arborées constituées d'arbres de 10 à 12 mètres de hauteur et de graminées (Guinko, 1984). Selon Ouédraogo (1996) la province du Boulkiemdé relève du secteur méridional de la zone centre dans la caractérisation des parcs agroforestiers du Burkina Faso. Les espèces de parcs dominantes dans ce secteur sont Vitellaria paradoxa (karité), Parkia biglobosa (néré), Azadirachta indica (neem) et Faidherbia albida (faidherbia).

Les enquêtes: Pour avoir le maximum de renseignements sur le sujet, un questionnaire a été élaboré et porte sur l'historique du peuplement du rônier, le mode de gestion, l'évolution des densités, les combinaisons culturales et les interactions rônier- cultures, la gestion des parcs à rônier, les usages connus des populations. Ce questionnaire a été administré à un échantillon de quarante producteurs, suivi d'interview de six (6) personnes ressources qui sont des chefs et des anciens de village. La méthode participative a été privilégiée pour l'identification des catégories socioprofessionnelles avec le recensement des personnes ressources. Le critère d'échantillonnage est l'âge qui varie de 40 à 85 ans avec une forte proportion des personnes âgées de plus de 50 ans $(70 \%)$ pour avoir un bon recul dans le temps.

Inventaires des plants de Borassus akeassii : Les inventaires ont été réalisés dans les parcs à Borassus akeassii sur vingt-deux (22) placettes de $50 \mathrm{~m} \times 50 \mathrm{~m}$. Les paramètres mesurés et les observations ont concerné le diamètre à hauteur de poitrine $(1,30 \mathrm{~m})$, le nombre total de plants observés en distinguant le nombre de plants adultes et le nombre de rejets; le niveau d'attaques et l'origine du plant qui peut être issu de semis directs, de Régénération Naturelles Assistées (RNA) ou de Plantations.

Traitement des données: Le pourcentage calculé résulte du rapport des valeurs attribuées au paramètre concerné et du total des valeurs de l'ensemble des paramètres. L'évaluation des usages du rônier a été faite par l'examen des utilisations des différentes parties de l'espèce et en référence du nombre de producteurs qui l'exploite c'est-à-dire le pourcentage de citation de l'usage 


\section{Yameogo et al. J. Appl. Biosci. 2016 Le rônier (Borassus akeassii B. O.G.) dans les parcs agroforestiers à}

Kokologho, Sakoinsé et Ramongo dans la province du Boulkiemdé, Centre-ouest du Burkina Faso

par les personnes interrogées. L'intensité de l'usage (U) est appréciée par des notes comprises entre 0 et 3 selon les cas suivants : Lorsque le pourcentage de citations est compris entre 60 à 100\%, la partie est très utilisée dans l'usage concerné et $U=3$; pour un pourcentage de citations compris entre 50 à $59 \%$, la partie est

\section{RESULTATS}

Historique des peuplements: Plusieurs versions existent quant à l'existence des rôniers dans les villages. Une des versions des villages de Kokologho et de Ramongo est que la plantation date de l'époque coloniale. Elle fait partie des travaux forcés imposés à chaque canton de l'époque. La plantation, l'arrosage et l'entretien des plants se faisaient par les villages voisins relevant de la chefferie de Kokologo et Ramongo. Une autre version date l'apparition des rôniers d'avant la colonisation. Les plants seraient propagés par des éléphants qui étaient présents dans la zone. Une dernière version soutient que les rôniers existent dans les villages du fait des inondations. Sous l'action de l'eau qui a joué le rôle de transporteur des graines, des plants ont poussé dans les bas-fonds et y demeurent jusqu'aujourd'hui. Mais tous sont unanimes que la première campagne de plantation du rônier a été réalisée avant l'indépendance du pays en 1960 et date d'une centaine d'années ; des plantations individuelles ont été ensuite mises en place. Les populations de Rallo reconnaissent que les peuplements ont été mis en place par les agents de l'État en l'occurrence ceux du service des Eaux et Forêts. II s'agit de peuplements issus de semis directs. D'après le chef de Sakoinsé: les rôniers viennent de Banfora à l'extrême sud-ouest du Burkina Faso depuis l'année de la construction de la préfecture de Saponé. Celle-ci devait être construite à Sakoinsé mais sous l'influence de chefs de villages voisins tels que Saponé et Kayao, le chef de Sakoinsé a permis que la préfecture soit construite à Kokologho prétextant que Sakoinsé est une zone rurale et pauvre. moyennement utilisée dans l'usage concerné et $U=2$. Dans le cas où ce pourcentage de citations est inférieur à $50 \%$ la partie est faiblement utilisée et $U=1$. Si aucun usage n'a été signalé $U=0$. La note totale $\mathrm{N}$ résulte de la somme totale des notes $U$ de chaque partie du rônier.

Caractéristiques des parcs à rônier : Les principales caractéristiques des parcs à rôniers relevées sont relatifs au statut foncier, le type de champs, les spéculations associées au rônier, les densités et les diamètres des plants, les attaques parasitaires observées ainsi que les mortalités des plants. Dans l'ensemble des trois villages d'étude, les gestionnaires des parcs sont à $82 \%$ propriétaires des parcelles, $9 \%$ sont des parcs communautaires, également $9 \%$ sont des exploitants emprunteurs. Les parcelles communautaires mises en place par l'administration coloniale sont actuellement gérées par les populations autochtones et les agents des Eaux et Forets. II ressort que $77 \%$ des parcs à rôniers sont des champs de case tandis que $23 \%$ sont des champs de village. On note un quasi absence de champs de brousse. Cela signifie que les rôniers ont été localisés à proximité des concessions ou un peu plus loin au sein des villages. Les spéculations en association avec le rônier sont principalement le sorgho et le mil, secondairement l'arachide, le riz, le pois de terre, le sésame, le maïs, le niébé et le soja. Les diamètres des plants de plus de $1,30 \mathrm{~cm}$ de haut peuvent être regroupés en quatre classes comme l'indique la figure 2. Les rejets constitués de plants de sont en faibles nombre et estimés à environ 3 plants/ha, ce qui révèle un caractère vieillissant des parcs à rôniers dans ces localités. Sans endommager les plants la principale attaque parasitaire est celle des termites retrouvés sur presque toutes les parcelles. Des oiseaux, des hirondelles colonisent les houppiers, abandonnent leurs déjections sur les plants et au sol. Des insectes perforateurs des bourgeons y sont également constatés. 


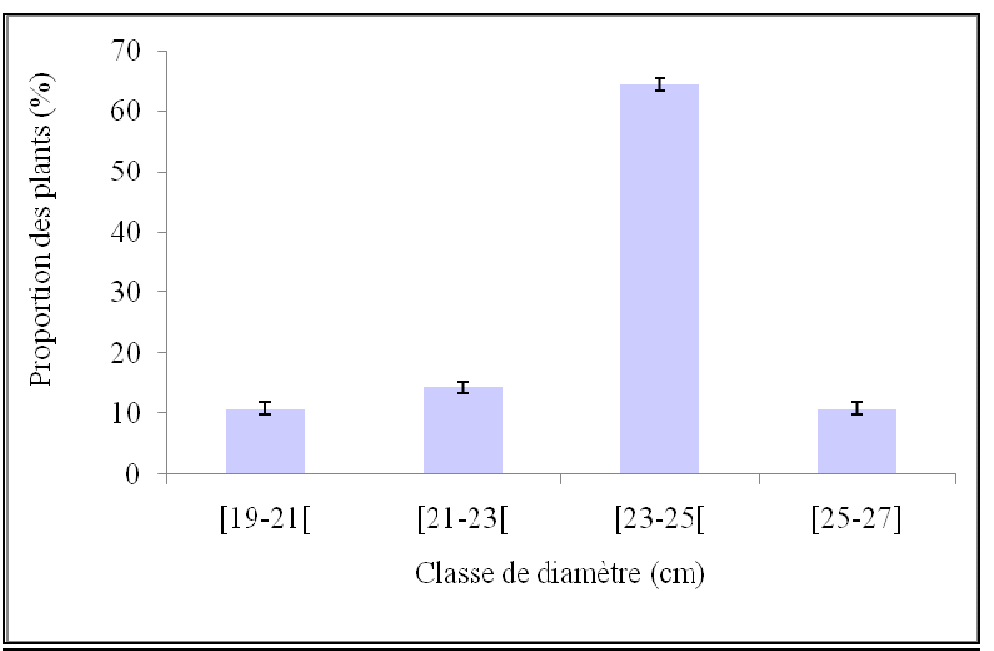

Figure 2 : Proportion des classes de diamètre des plants inventoriés dans les parcs à rôniers à Kokologo, Sakaoinsé et Ramongo

Perception des interactions rônier-cultures : On note que $6 \%$ des personnes interrogées attestent ignorer les interactions entre le rônier et les cultures. Les perceptions que les $94 \%$ ont de ces interactions émanent de leurs observations sur le terrain et elles peuvent être regroupées en quatre catégories d'impacts :

- Impacts sur la fertilité du sol : il est ressorti des entretiens que la pulpe des fruits matures et immatures tombés dans les champs se décompose et constitue une source de fertilisation du sol. II en est de même pour les feuilles du rônier bien que très lentes en décomposition. Des oiseaux et divers autres animaux séjournent constamment sur les houppiers du rônier et $y$ défèquent. Les déjections tombées au sol contribuent à fertiliser le sol. De plus l'humidité du sol parait plus importante dans une surface d'au moins 2 mètres autour du rônier que loin du rônier.

- Impacts sur le développement des cultures : les producteurs perçoivent de meilleurs croissance et développement des cultures autour du rônier qui s'expriment par l'amélioration de la qualité du sol.

- Impacts sur le développement du rônier: comparativement aux plants de rônier isolés, ceux qui sont dans les champs sont visiblement épanouis et sont plus productifs en feuilles et fruits. En effet ces plants bénéficient des traitements culturaux et surtout des labours effectués en faveur des cultures au cours de la saison pluvieuse, rendant le sol plus poreux.
- Bonne coexistence entre les racines: les producteurs spéculent sur une harmonieuse occupation du sol par les racines des cultures et du rônier.

Les stratégies de gestion de ces peuplements de rôniers seraient influencées par les perceptions et l'importance socioéconomique de cette espèce.

Gestion des peuplements

Usages du rônier connus des populations: Les résultats présentés au Tableau 1 attestent que le rônier est peu exploité par les populations du Centre-ouest. Les principales utilisations concernent les feuilles et les fruits. Les feuilles sont utilisées dans l'artisanat notamment la confection de paniers, les pétioles pour les tamis. Cependant la plupart des artisans n'est pas des ressortissants des villages mais des artisans installés dans la ville de Koudougou. Ceux-ci viennent acheter ou collecter gratuitement les feuilles. Une feuille coûte en moyenne $75 \mathrm{~F} \mathrm{CFA}$. La pulpe sucrée du fruit à maturité est consommée par les enfants. Les autres parties du rônier telles que le stipe, les inflorescences, les racines et la sève sont très faiblement exploitées. La sève n'est pas utilisée pour sa vertu alimentaire mais pour un intérêt médicinal. 
Yameogo et al. J. Appl. Biosci. 2016 Le rônier (Borassus akeassii B. O.G.) dans les parcs agroforestiers à Kokologho, Sakoinsé et Ramongo dans la province du Boulkiemdé, Centre-ouest du Burkina Faso

Tableau 1: Appréciation de l'intensité des usages du rônier

\begin{tabular}{llllllll}
\hline \hline $\begin{array}{l}\text { Usage } \\
\text { Partie }\end{array}$ & Alim. & Med. & Fourr. & Art. & Fert. & Const. & Note N \\
\hline Feuilles & 0 & 0 & 3 & 3 & 1 & 1 & $08 / 18$ \\
Fruits & 3 & 0 & 0 & 0 & 0 & 0 & $03 / 18$ \\
Stipe & 0 & 0 & 0 & 1 & 0 & 1 & $02 / 18$ \\
Inflorescences & 1 & 1 & 0 & 0 & 0 & 0 & $02 / 18$ \\
Pétioles & 0 & 0 & 0 & 1 & 0 & 0 & $01 / 18$ \\
Racines & 0 & 1 & 0 & 0 & 1 & 0 & $02 / 18$ \\
Sève & 0 & 1 & 0 & 0 & 0 & 0 & $01 / 18$ \\
\hline \hline
\end{tabular}

Pourcentage de citations entre 60 à 100\%, la partie est très utilisée dans l'usage concerné et $\mathrm{U}=3$

Pourcentage de citations entre 50 à $59 \%$, la partie est moyennement utilisée dans l'usage concerné et $U=2$. Pourcentage de citations est inférieur à $50 \%$ la partie est faiblement utilisée dans l'usage concerné et $U=1$. Si aucun usage n'a été signalé $U=0$

Évolution des densités des peuplements: Les évolutions des densités de peuplements s'observent à la régression chez $59 \%$ des exploitants, à la stabilité chez $14 \%$ et à la croissance chez $27 \%$. D'une part les facteurs de stabilité et de régression sont: la forte pression exercée par les animaux sur les jeunes pousses: moutons, chèvres, ânes, bœufs ; la gelée des fruits immatures est consommée par les enfants, ce qui empêche les fruits d'atteindre la maturité ; les fruits murs sont exportés hors des champs et consommés par les enfants ; l'action de vents violents qui ont déraciné des plants ; les hirondelles ont souvent détruit des plants de rônier par consommation du bourgeon terminal; la destruction de jeunes pousses pendant les labours. Par ailleurs il ressort des entretiens et des observations sur le terrain que diverses autres espèces tendent à remplacer Borassus akeassii dans les parcs initialement dédiés à cette espèce. Ces espèces concurrentes comme illustrées par les figures 3 et 4 sont par ordre d'importance décroissante Azadirachta indica, Eucalyptus camaldulensis, Lannea microcarpa, Faidherbia albida et Senna siamea. A Sakoinsé il existe un bosquet de
Azadirachta indica qui initialement était celui de rôniers. En 1975 les jeunes gens du village ont détruit les rôniers pour mettre en place un terrain de sport. Saisis par le service des Eaux et Forets, ils ont été condamnés à planter Azadirachta indica en remplacement du rônier détruit. Par la zoochorie et par voie de plantations, Azadirachta indica apparait un remplaçant potentiel du rônier dans les champs. Eucalyptus camaldulensis y est introduit pour la production de bois source de revenus monétaires, Lannea microcarpa pour son rôle alimentaire et commercial. Faidherbia albida est exploité comme espèce fourragère et de fertilisation du sol. Les populations reconnaissent l'importance médicinale de Senna siamea. D'autre part les facteurs de croissance sont la protection des rôniers par les agents des Eaux et Forets ; les régénérations naturelles assistées issues des fruits murs abandonnés dans les parcs; les plantations dans les parcelles privées; les semis directs. Particulièrement à Sakoinsé, les peuplements sont en bonne évolution pour deux raisons: les artisans qui confectionnent les articles ménagers ont tendance à faire du semis directs. 


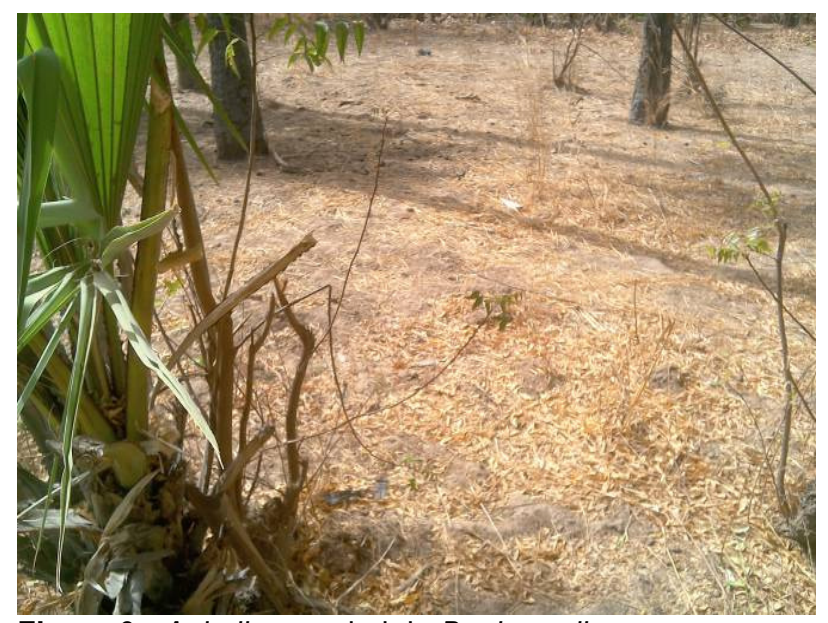

Figure $3: A$. indica au pied de $B$. akeassii

Entretien et Méthodes de renouvellement du patrimoine: Comme l'indique la figure 5 les actions d'entretiens en faveur de Borassus akeassii sont les actions de protection, l'arrosage d'eau, le désherbage et l'élagage. Dans le paysage champêtre du Centre-ouest les rôniers bénéficient principalement des travaux de désherbage réalisés par tous les paysans au cours de la saison pluvieuse, ensuite viennent les actions de protection reconnues par $28 \%$ des personnes interrogées. II s'agit de la répression recommandée par les agents des Eaux et Forets en cas de destruction des plants et la protection contre les feux de brousse. Seulement $22 \%$ des gestionnaires de parcs pratique l'élagage des pétioles qui débarrasse les stipes des gaines mortes et permet de mieux gérer les dimensions des houppiers en faveur des cultures environnantes.

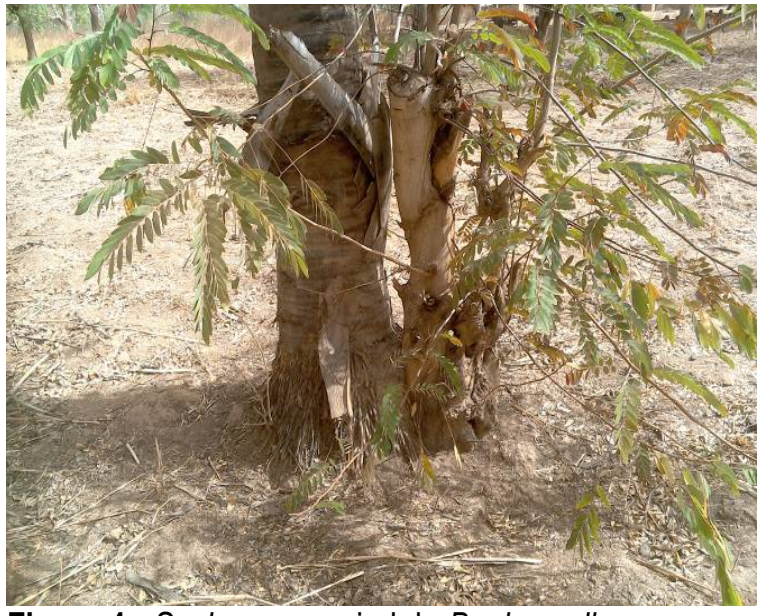

Figure 4 : S. siamea au pied de B. akeassii

L'eau étant une denrée rare en saison sèche en milieu rural, 20\% des gestionnaires de parcs reconnaissent avoir arrosé les jeunes pousses de rônier. Concernant les méthodes de renouvellement, afin d'assurer la pérennité des espèces ligneuses, $39 \%$ des gestionnaires de parcs à rôniers ont recours à la régénération naturelle assistée (RNA), $11 \%$ à la plantation de jeunes plants (PL) et $5 \%$ aux semi-directs (SD) (figure 6 ). Ainsi, le paysan compte beaucoup plus sur la régénération naturelle que sur les autres méthodes. Ces pratiques selon leur intensité peuvent influencer l'état des peuplements. Cependant on a noté qu'une forte proportion de ces gestionnaires de parcs, soit 44\% n'entreprennent aucune action de renouvellement des peuplements. Celle-ci se limite à la protection des plants existants ou hérités.

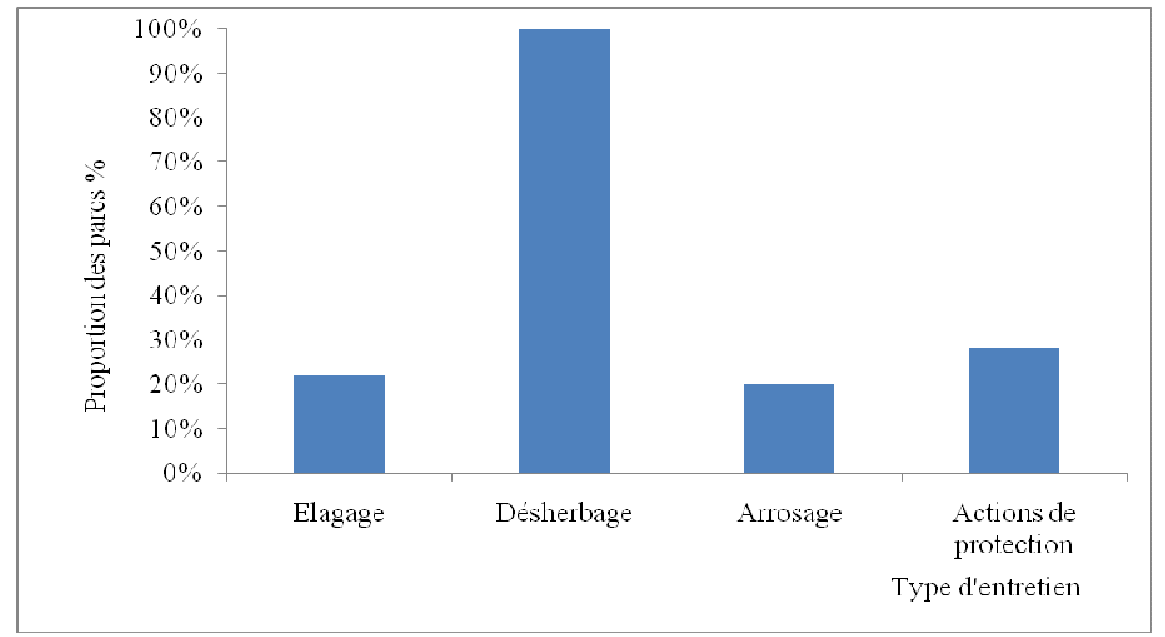

Figure 5 : Les types d'entretien des parcs à rôniers à Kokologo, Sakaoinsé et Ramongo 


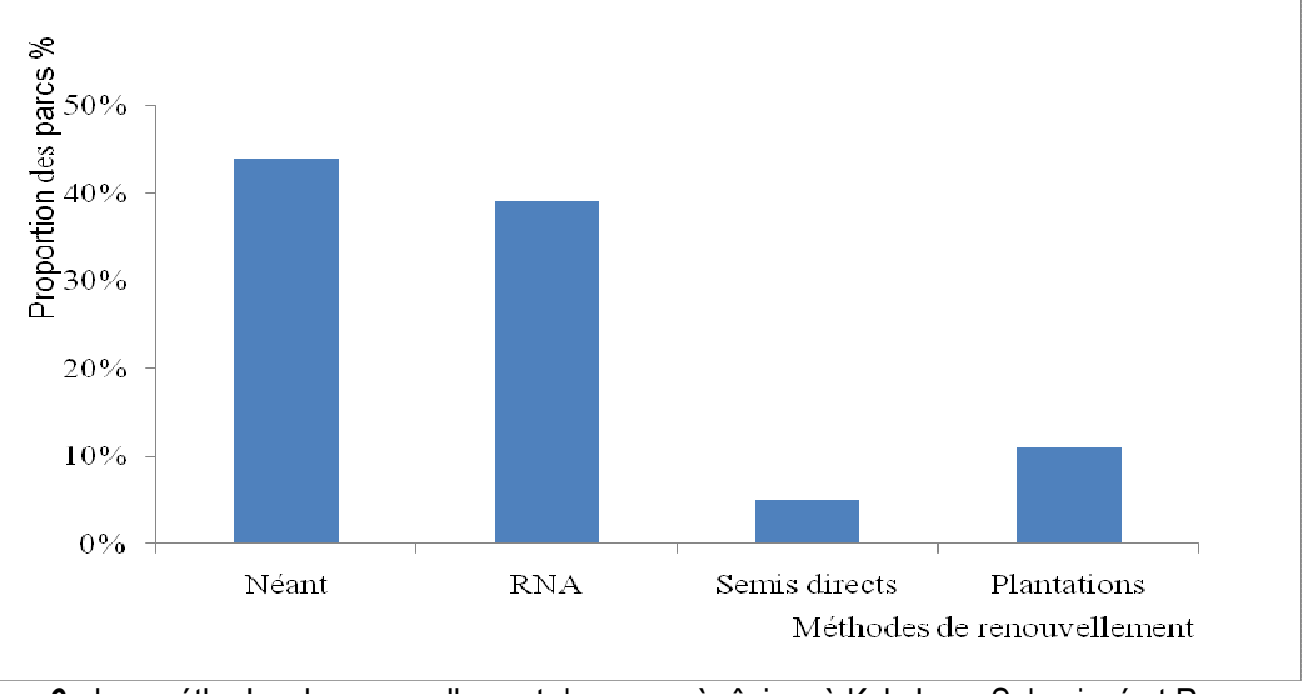

Figure 6 : Les méthodes de renouvellement des parcs à rôniers à Kokologo, Sakaoinsé et Ramongo

Contraintes de gestion des parcs : Les contraintes de gestion des parcs à rôniers révélées par diverses proportions des personnes interrogées sont de plusieurs ordres : naturel, technique, financier et anthropique. Les sécheresses, le manque d'eau et les vents violents $(100 \%)$ sont les facteurs naturels. Les insuffisances techniques $(80 \%)$ se résument à l'exploitation des fruits qui limite la RNA, il y a une méconnaissance de la technique de coupe des feuilles pour des besoins artisanaux. Le bourgeon terminal est souvent coupé et en conséquence les rôniers meurent. Toutes les personnes interrogées sont unanimes qu'il y a de très fortes pressions des ruminants sur les jeunes pousses du rônier. Le manque de moyens financiers (87\%) auquel les producteurs font face constitue un handicap pour les achats de plants de rônier et pour la mise en place de dispositifs de protection des jeunes plants. Relativement à la biologie de l'espèce, $80 \%$ des producteurs ont reconnu que les plants de rônier se développent mieux en bas-fonds. La lenteur du processus de germination des graines de rôniers limite à la fois la disponibilité des plants et l'engagement des producteurs à créer les pépinières.

\section{DISCUSSION}

En ce qui concerne les peuplements à rôniers, plutôt que ce soit l'un ou l'autre des trois récits qui explique leur origine au Centre-ouest, nous pouvons retenir que les actions conjuguées de ces récits pourraient en expliquer. D'une part l'ICRAF (1993) rapporte que les forêts parcs à rôniers sont quelques fois créées par les éléphants friands du fruit et qui participent à la dissémination des graines. D'autre part, l'époque coloniale durant laquelle
Souhaits d'amélioration : Les souhaits d'amélioration formulés par l'ensemble des populations des trois localités se résument en huit points essentiels :

1. la réalisation de voyages d'étude sur l'importance et les usages du rônier ;

2. la création de pépinières de plants de rôniers pour les villages ou octrois de plants ;

3. des prises de mesures fortes par les services des Eaux et Forets pour la protection des plants y compris la production fruitière ;

4. le renforcement des capacités des producteurs à la production de plants de rôniers eu égard aux difficultés de germination des graines ;

5. la création de forages pour une disponibilité d'eau pour l'arrosage des plants en saison sèche ;

6. la facilitation d'accès à de grilles de protection des jeunes pousses du rônier contre le broutage des animaux;

7. la sensibilisation des jeunes et des enfants en particulier à ne pas cueillir les fruits immatures et matures tant que les densités de peuplements demeurent faibles. 8. l'introduction d'une diversité de palmiers entre autres le cocotier.

des plantations d'arbres ont été largement réalisées pourrait justifier l'introduction du rônier dans le paysage du centre-ouest. Enfin le rônier est perçu comme une espèce hydrochorique, par conséquent on peut le retrouver dans les dépressions inondées périodiquement, dans les terrains marécageux, au bord des lacs et des rivières (Alexandre, 2002) comme c'est le cas dans les sites d'études. Bien que protégé par les populations, la 


\section{Yameogo et al. J. Appl. Biosci. 2016 Le rônier (Borassus akeassii B. O.G.) dans les parcs agroforestiers à}

Kokologho, Sakoinsé et Ramongo dans la province du Boulkiemdé, Centre-ouest du Burkina Faso

faiblesse des densités du rônier relève d'une défaillance dans les actions de gestion durable des espèces utilitaires attribuable aux acteurs du développement et de la recherche scientifique. Au Burkina Faso le rônier fait partie des espèces protégées. Selon une étude de l'IUCN (2015) le rônier est compté parmi les vingt-trois espèces bénéficiant d'une protection particulière. Alors des actions devaient résulter de ce statut notamment des actions de sensibilisations et de transfert de connaissances dans les zones de faibles densités. En référence aux résultats d'inventaire, quatre facteurs illustrent cette défaillance de la gestion durable du rônier dans les zones étudiées :

(i) les peuplements sont vieillissants ;

(ii) l'ignorance des méthodes d'usages du rônier et le manque de transfert de technologie des régions de l'Ouest et de l'Est vers la région du Centre-ouest ;

(iii) les causes de régression des densités de rôniers identifiées par les personnes interrogées ;

(iv) le manque de plantations individuelles et de pépinières expliqué par des impacts socioéconomiques modestement perçus par les populations. Ces facteurs justifient la passivité des producteurs dans les phénomènes de concurrence observés entre le rônier et d'autres espèces qui sont plus impliquées dans des usages d'espèces ligneuses connus des populations. Mais force est de reconnaitre qu'en agroforesterie, on ne peut remplacer une composante ligneuse par une autre sans au préalable identifier les types d'interactions arbres-cultures qui en découleront, tout en prenant en

\section{REMERCIEMENTS}

Les auteurs remercient les populations de la commune de Kokologho et les Chefs et Anciens des villages de Kokologho, Sakoinsé et Ramongo pour leur disponibilité à abriter les travaux. Ils remercient la Direction

\section{REFERENCES}

Alexandre DY. 2002. Planté, Semé, Protégé. Peuplements anciens et actuels des forêts tropicales 228-234.

Arbonnier M, 2002. Arbres, arbustes et Lianes des zones sèches d'Afrique de l'Ouest. CIRAD-MNHNUICN (Editor), 2ème édition, Artecom 89, Pontsur-moyenne, France 573 pp.

Bayala J, Teklehaimanot Z, Ouédraogo SJ. 2002. Millet production under crown pruned trees of Parkia biglobosa and Vitellaria paradoxa in Burkina Faso. Agroforestry Systems 54 : 203 - 214.

Bayton RP, Ouédraogo A, Guinko S. 2006. The genus Borassus (Arecacea) in West Africa with a compte les densités de peuplements à recommander. L'arbre idéal pour le recyclage des nutriments est celui qui possède des racines profondes et dont leur extension latérale est peu perceptible dans les couches superficielles du sol (Noordwijk et Purnomosidhi, 1995, Bayala et al., 2002). Les interactions rôniers-cultures ont été élucidées par Yaméogo (2008). Le présent travail vient en appuis à plusieurs travaux qui ont été menés pour contribuer à la mise en exergue de Borassus akeassii en Afrique de l'Ouest (Arbonnier 2002; Yameogo, 2008 ; Gbesso et al. 2014). Notons que pour le cas spécifique du Centre-ouest du Burkina Faso au regard des contraintes énumérées et des souhaits formulés par les populations interrogées, une étape primordiale pour une gestion durable demeure un travail de fonds se résumant à l'information-sensibilisationformation sur l'importance biophysique, socioéconomique du rônier et couronné par des transferts de technologies. En dépit de ces difficultés de gestion du rônier des fondements de gestion durable existent et les bases desquelles on peut partir existent parmi les producteurs qui font recours à la régénération naturelle assistée (RNA), aux plantations de jeunes plants (PL) et aux semidirects (SD). Un autre groupe de population cible favorable aux actions de gestion durable du rônier est constitué de ceux qui perçoivent déjà et exploitent les valeurs économiques et sociales des différentes parties du rônier.

Provinciale de l'Environnement et des Eaux et Forets du Boulkiemdé pour la collaboration.

description of a new species from Burkina Faso. Journal of the Linnean Society, 150: 419-427.

Gbesso F, Yedomonhan H, Tente B, Akoegninou A. 2014. Distribution géographique de Borassus aethiopum Mart et caractérisation phytoécologique de leurs habitats du Benin. Journal of Applied Biosciences 74 :6099-6111.

Guinko S. 1984. Végétation de la Haute - Volta. Thèse de Doctorat d'État. 2 Tomes. Université de Bordeaux III, France, $394 \mathrm{p}$.

ICRAF, 1993. Faidherbia albida dans les zones tropicales d'Afrique de l'Ouest. Nairobi, Kenya. $206 \mathrm{pp}$. 
IUCN 2015. Certification des PFNL au Burkina Faso. IUCN-Burkina, Ouagadougou, 34 pp.

Noordwijk MV, Purnomosidhi P. 1995. Root architecture in relation to tree-soil-crop interactions and shoot prunning in agroforestry. Agroforestry Systems $30: 61-117$.

Ouédraogo A. 1999. Biomorphologie des rôniers (Borassus L.) du Burkina Faso. Mém. DEA. Université de Ouagadougou, Burkina Faso. 69 pp.

Ouédraogo SJ. 1996. Étude du fonctionnement et de la dynamique des parcs agroforestiers du Burkina Faso. INERA/ ORSTOM (Editor), Ouagadougou, Burkina Faso. 42 pp.

Yameogo J, 2008. Contribution des parcs à Borassus akeassii Bayton, Ouédraogo et Guinko au fonctionnement des systèmes de productions au sud-ouest du Burkina Faso. thèse de l'Université de Ouagadougou. 188 pp.

Yaméogo J, Ouédraogo SJ, Bayala J, Belem/Ouedraogo M. 2010. Medicinal and Food Potentials of Seventeen Favorites Tree Species in the Agroforestry Parklands in the southwestern Burkina Faso. Global Science Books 4: 55-61

Yaméogo J. 1999. Étude de l'association du maïs au rônier dans le Sud-ouest du Burkina Faso. Mém. DEA. Univ. de Ouagadougou, Burkina Faso. 66 pp. 